BMJ Open

Diabetes

Research

\& Care

\section{Glutathione S-transferases gene polymorphism influence on the age of diabetes type 2 onset}

To cite: Klusek J,

Błońska-Sikora E, Witczak B, et al. Glutathione $S$-transferases gene polymorphism influence on the age of diabetes type 2 onset. BMJ Open Diab Res Care 2020;8:e001773. doi:10.1136/ bmjdrc-2020-001773

Received 15 July 2020 Revised 7 September 2020 Accepted 21 October 2020

\section{Check for updates}

(C) Author(s) (or their employer(s)) 2020. Re-use permitted under CC BY-NC. No commercial re-use. See rights and permissions. Published by BMJ.

${ }^{1}$ Collegium Medicum, Jan Kochanowski University of Kielce, Kielce, Poland

${ }^{2}$ Świętokrzyskie Mother and Newborn Centre, Kielce, Poland ${ }^{3}$ First Faculty of Medicine, Medical University of Warsaw, Warszawa, Poland

${ }^{4}$ Institute of Biology, Jan Kochanowski University of Kielce, Kielce, Poland

Correspondence to Justyna Klusek; Jsklusek@ujk.edu.pl

\section{ABSTRACT}

Introduction Type 2 diabetes (T2D) is a multifactorial disease affecting mostly adults older than 40 years. The aim of the study was to examine GST gene polymorphism influence on the risk of T2D, especially in young adults. Research design and methods 200 diabetic patients and 221 healthy controls participated in this study. Three GST gene polymorphism have been analyzed: GSTP1 (singlenucleotide polymorphism $\mathrm{Il}_{105} \mathrm{Val}$ ), homozygous deletion of GSTT1 (null/null) and GSTM1 (null/null), using TaqMan real-time quantitative PCR.

Results The distribution of examined polymorphisms was similar in patient group and control group. Statistically significant differences were demonstrated for the combination of GSTP1 Val/Val and GSTT1 null/null genotypes between patients diagnosed before 40 years of age and healthy people $(12.5 \%$ vs $0.9 \%, p=0.016)$. Moreover, all three examined gene polymorphism together (GSTP1 Val/Nal, GSTM1nul/null and GSTT1 null/null genotype) was observed in $12.5 \%$ of patients diagnosed before 40 years of age and in $0.5 \%$ of healthy individuals $(\mathrm{p}=0.013)$.

Conclusion In conclusion, the results suggest that GST polymorphism may be one of the risk factors for developing $\mathrm{T} 2 \mathrm{D}$ at a younger age than the T2D population average.

\section{INTRODUCTION}

Type 2 diabetes (T2D) is a global public health problem that is evolving with the increasing prevalence of obesity, unhealthy lifestyle (especially western-style diet and low physical activity) and the population's aging problem. The disease affects mostly adults, but also children and adolescents, especially in high-income countries. ${ }^{1}$ According to the International Diabetes Federation (IDF), T2D is recognized in over $90 \%$ of cases with diabetes mellitus. ${ }^{2}$ In Poland in 2017, there were over 2 million adults suffering from T2D (IDF statistics) $^{3}$ and by 2030, the number will have increased to 2.5 million. ${ }^{4}$ It is characterized by chronic hyperglycemia and other metabolic alterations resulting from a lack of insulin in the body and insulin resistance of tissues. ${ }^{15}$ Pathogenesis of the disease is

\section{Significance of this study}

What is already known about this subject?

- Most type 2 diabetes (T2D) cases are diagnosed after the age of 40 years.

- GST gene family polymorphism results in decreased cell protection against environmental pollutants, carcinogens, oxidative stress products and a wide spectrum of xenobiotics.

- Studies focusing on GST gene family polymorphism as a risk factor of T2D published in the last few years demonstrated ambiguous results.

What are the new findings?

- Our study identified association between GST gene family polymorphism and early onset of T2D.

- It was the first study of GSTM1, GSTT1 and GSTP1 gene polymorphisms in the Polish population of patients with diabetes.

How might these results change the focus of research or clinical practice?

- Genetic tests might be used to predict the risk of developing T2D in adults younger than 40 years if our results are confirmed on a larger cohort.

complex and involves not only environmental factors but also genetic vulnerability. Most of T2D cases are diagnosed after 40 years of age, especially in subjects with obesity or overweight following a western diet lifestyle, ${ }^{46}$ but there is also a group of younger patients. The development of molecular technologies in the twenty-first century has allowed researchers to focus on individual genetic predispositions to T2D. It is considered that antioxidant and detoxification gene polymorphism play an important role in the risk of T2D. ${ }^{78}$ Some of them are GST genes coding glutathione S-transferases which are phase II key detoxifying enzymes. These enzymes are involved in the glutathione-coupling reactions of a broad range of electrophilic substances, thus facilitating their detoxification, metabolism and excretion. That is why they play an important role in cell protection against environmental 
pollutants, carcinogens, chemotherapeutics, oxidative stress products and a wide spectrum of xenobiotics. GSTP1, GSTM1 and GSTT1 gene polymorphisms result in low enzyme activity as reported for the GST gene family. Loss or reduction of enzyme activity leads to the reduction of the ability to neutralize toxins. ${ }^{67}$ There have been many studies focused on GST gene polymorphism as a risk factor of T2D in last few years, but the results are ambiguous. ${ }^{12-12}$ It is worth mentioning that only a few of them were conducted in Europe. ${ }^{111} 12$ The aim of the study was to examine how an individual's genetic makeup can have an impact on the risk of T2D, especially in young adults.

\section{RESEARCH DESIGN AND METHODS}

Population sample

This study was conducted in Kielce (Poland). Sampling was done from June to December 2019. Patients were recruited from the diabetic outpatient center, the control was unrelated volunteers aged over 18 years with no diabetic symptoms, no history of fasting glucose level exceeded and no family history of glucose metabolism disorders. Patients were enrolled following the inclusion criteria: age over 18 years and diagnosis of T2D, the exclusion criteria being history of endocrine disorders, known malignancies, alcoholism, patients with diabetes secondary to chronic pancreatitis, Cushing's disease with treatment that can induce hyperglycemia, type 1 diabetes, pregnant and lactating women. The T2D diagnosis was determined by a diabetologist according to the (revised) criteria of the American Association of Diabetology. ${ }^{13}$ All procedures of the study were conducted according to the principles of the Declaration of Helsinki.

After the subjects of both groups signed written consent forms for the genetic testing of GST genes, clinical data and blood samples were taken (test tubes with EDTA provided by Sarstedt) by a qualified nurse. Appropriately coded samples were frozen at $-20^{\circ} \mathrm{C}$ until the time of genetic testing.

\section{Genotyping}

Peripheral blood leukocytes were the material for genetic testing. The genomic DNA was extracted from blood samples using the Genomic Micro AX Blood Gravity kit from A\&A Biotechnology (Gdynia, Poland). The purity and concentration of the isolated DNA were evaluated spectrophotometrically at $260 \mathrm{~nm}$ and $280 \mathrm{~nm}$ (NanoDrop 2000, Thermo Fisher Scientific). Analysis of the single nucleotide polymorphism (rs1695) of the GSTP1 gene was conducted using the TaqMan quantitative PCR (qPCR) method-endpoint genotyping (Assay ID C_3237198_20). The deletion of copies of genes GSTT1 (Assay ID Hs00010004_cn) and GSTM1 (Assay ID Hs02575461_cn) was analyzed using the qPCR relative quantification method with the TERT control gene. In all cases, the LightCycler 96 instrument and TaqMan primer/probe kit (produced by Life Technologies) were used. PCR amplification using $\approx 10$ ng of genomic DNA was performed with an initial step of $95^{\circ} \mathrm{C}$ for $10 \mathrm{~min}$ followed by 50 cycles of $95^{\circ} \mathrm{C}$ for $15 \mathrm{~s}$ (denaturation step) and $60^{\circ} \mathrm{C}$ for $90 \mathrm{~s}$ (annealing and elongation steps).

\section{Statistical analysis}

Quantitative data are described by means, SD, medians, quartiles and range (minimum and maximum). Categorical data were summarized by frequencies and percentages. Group comparisons were performed using the $\chi^{2}$ or Fisher's exact test for categorical variables, the t-test for quantitative, normally distributed variables or the MannWhitney test for quantitative, non-normally distributed variables (normality of distribution was checked with the Shapiro-Wilk test). Statistical tests were two-tailed and p-value of less than 0.05 was considered significant. The Bonferroni correction was applied in case of multiple comparisons. Departure in the distribution of genotypes from Hardy-Weinberg equilibrium was assessed through the $\chi^{2}$ test. All statistical analyses were performed using R (V.3.1.2; The R Foundation for Statistical Computing, Vienna, Austria).

\section{RESULTS}

In our case-control study, we included a total of 421 participants: 200 unrelated patients with T2D and control group consisting of 221 unrelated individuals without T2D. Demographic characteristics of both group is presented in table 1. GST gene polymorphism frequency in the examined population does not differ statistically from the epidemiological data for the Caucasian race (table 2). ${ }^{14}$

The distribution of examined polymorphisms was similar in patient group and control group. Moreover, there were no statistical differences between GST genotypes distribution between groups when the analysis was conducted for each sex separately (table 3 ).

The analysis of the gene polymorphism was also performed in the groups of patients differing in the age of T2D diagnosis.

Patients were divided into two groups: group A $(n=16)$ patients with T2D diagnosed before 40 years; group B $(n=184)$ patients with T2D diagnosed after and at the age of 40 years.

The rationale for this division is that T2D is mostly diagnosed after 40 years of age. ${ }^{4}$ Moreover, the US Preventive Services Task Force recommends screening for T2D, individuals 40 to 70 years of age who are overweight or obese. ${ }^{5}$ The control group were people with no T2D aged $\geq 40$ years (group $\mathrm{C}, \mathrm{n}=212$ ). The results of this analysis are shown in table 4 .

When analyzing each of the GST genes separately, the difference in frequency of their polymorphism was observed but statistically insignificant. For example, GSTP1 Val/Val genotype was found in $18.8 \%$ of group A and in $10.3 \%$ of group B ( $\mathrm{p}=0.39)$ and in $9.9 \%$ of group $\mathrm{C}(\mathrm{p}=1.0)$. GSTT1 null/null genotype was found in $31.2 \%$ 
Table 1 Demographic characteristic of patients and controls

\begin{tabular}{|c|c|c|c|}
\hline & Patients $(n=200)$ & Controls $(n=221)$ & $P$ value \\
\hline Age & & & $<0.001$ \\
\hline Missing data & 0 & 2 & \\
\hline Mean (SD) & $66.8(8.07)$ & $53.9(10.22)$ & \\
\hline $\mathrm{Age}^{*}$ & & & 0.8131 \\
\hline Missing data & 0 & 2 & \\
\hline Mean (SD) & $54.1(10.74)$ & $53.9(10.22)$ & \\
\hline Sex & & & $<0.001$ \\
\hline Female & 97 (48.5\%) & $167(75.6 \%)$ & \\
\hline Male & 103 (51.5\%) & $54(24.4 \%)$ & \\
\hline $\mathrm{BMI}$ & & & $<0.001$ \\
\hline Missing data & 1 & 2 & \\
\hline Mean (SD) & $30.9(4.8)$ & $27.2(4.7)$ & \\
\hline Median (Q1, Q3) & 30.7 (27.8 to 33.8 ) & 26.8 (23.6 to 29.9 ) & \\
\hline Range & $19.2-46.5$ & $17.3-41.5$ & \\
\hline
\end{tabular}

*In patient group age at a diagnosis of type 2 diabetes.

$\mathrm{BMI}$, body mass index.

of group A and in $24.5 \%$ of group B $(p=0.55)$ and in $18.9 \%$ of group $\mathrm{C}(\mathrm{p}=0.18)$.

In the combined analysis of GST gene polymorphism, the differences were more extensive (table 4). GSTP1 $\mathrm{Val} / \mathrm{Val}$ combined with GSTT1 null/null was found in $12.5 \%$ of group A and in $2.2 \%$ of group B $(p=0.13)$ and in $0.9 \%$ of group C. This result was statistically significant ( $\mathrm{p}=0.016)$. GSTP1 Val/Val combined with GSTM1 null/ null was found in $18.8 \%$ of group A and in $6.5 \%$ of group B $(\mathrm{p}=0.14)$ and in $4.2 \%$ of group C $(\mathrm{p}=0.082)$. GSTT1 null/null combined with GSTM1 null/null was found in $18.8 \%$ of group A and in $12.5 \%$ of group B $(p=0.21)$ and in $8.5 \%$ of group $\mathrm{C}(\mathrm{p}=0.14)$. All three examined gene polymorphism together (GSTP1 Val/Val, GSTM1 null/null and GSTT1 null/null genotype) was observed in $12.5 \%$ of group A, $1.6 \%$ of group B $(\mathrm{p}=0.052)$ and $0.5 \%$ of group C $(p=0.013)$.
Patients with T2D diagnosed before 40 years did not differ from patients with T2D diagnosed after and at the age of 40 years in terms of body mass index (BMI): 29.9 (SD 6.2) versus 31.0 (SD 4.6); $\mathrm{p}=0.4$.

It suggests that other causes may be implicated in the disease development in younger age, for example, genetic vulnerability. However, the size of each group with the age division is small and obtained results require confirmation on a larger cohort.

\section{DISCUSSION}

Most current studies concerning genetic factors of T2D are conducted in Asia, because it is a major area of the rapidly emerging T2D global epidemic. Some of these studies confirm a relationship between particular GST gene polymorphism and the risk of the disease. ${ }^{7015-18}$ For

Table 2 GST polymorphism frequency in patient group with type 2 diabetes and in control group

\begin{tabular}{|c|c|c|c|c|}
\hline & Total & Patients & Control group & \multirow[b]{2}{*}{$P$ value } \\
\hline & $\mathrm{N}=421$ & $\mathrm{n}=\mathbf{2 0 0}$ & $\mathrm{n}=221$ & \\
\hline GSTP1* & & & & 0.91 \\
\hline Wild type (lle/lle) & $191(45.4 \%)$ & 89 (44.5\%) & $102(46.2 \%)$ & \\
\hline Heterozygous (lle/Val) & $186(44.2 \%)$ & 89 (44.5\%) & 97 (43.9\%) & \\
\hline Homozygous (Val/Val) & $44(10.5 \%)$ & $22(11.0 \%)$ & $22(10.0 \%)$ & \\
\hline GSTT1 & & & & 0.26 \\
\hline Wild type & $327(77.7 \%)$ & $150(75.0 \%)$ & 177 (80.1\%) & \\
\hline Null/null & $94(22.3 \%)$ & $50(25.0 \%)$ & $44(19.9 \%)$ & \\
\hline GSTM1 & & & & 0.47 \\
\hline Wild type & 232 (55.1\%) & 106 (53.0\%) & 126 (57.0\%) & \\
\hline Null/null & 189 (44.9\%) & 94 (47.0\%) & 95 (43.0\%) & \\
\hline
\end{tabular}

${ }^{*}$ Hardy-Weinberg equilibrium is not disturbed (patients: $\chi^{2}=0.001, p=0.97$; control group: $\chi^{2}=0.023, p=0.88$ ). 
Table 3 GST polymorphism frequency in patient group with type 2 diabetes and in control group with sex division

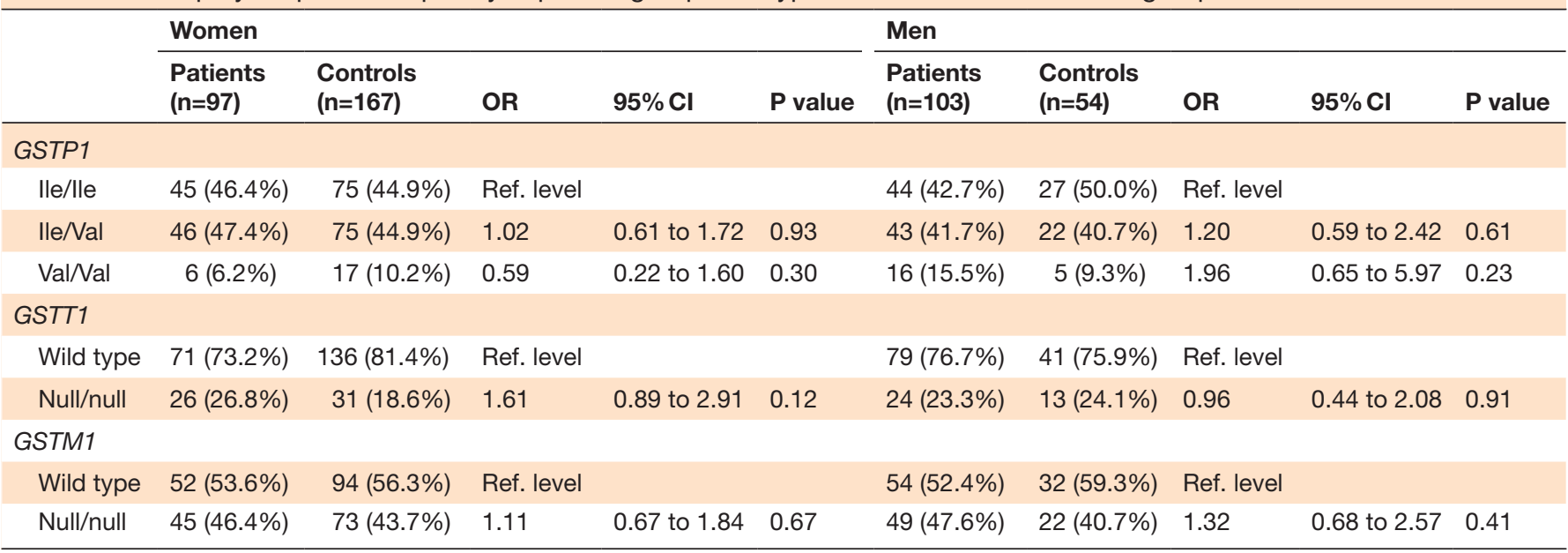

example, according to Banerjee $e t a l$, the null/null allele combination of GSTM1 and GSTT1 increases the disease risk up to 1.7 -fold. ${ }^{15}$ Other studies, both conducted in the north India, showed the combined effect of GSTM1, GSTT1 and GSTP1 polymorphism on T2D risk. ${ }^{17}{ }^{18} \mathrm{~A}$ systematic review of 19 studies has shown that individually or a combination of GSTT1null/null and GSTM1null/ null genotypes are associated with T2D. ${ }^{16}$ Another study, conducted in Iran, revealed that GSTP1Ile105Val polymorphism is associated with an increased risk of newonset diabetes mellitus after liver transplantation..$^{10} \mathrm{On}$ the other hand, a meta-analysis of 18 studies has shown no significant association between GSTP1 polymorphism and the risk of T2D. ${ }^{19}$ Results of our study has shown only slight differences in GST gene polymorphism frequency between patients with T2D and healthy controls, statistically not significant (table 2). The differences in the results may result from ethnic, and therefore genetic differences between the Asian and Caucasian races, as well as from a small size of the analyzed population. However, by analyzing the distribution of polymorphisms in groups that take into account the age at which the participant contracted T2D, the differences were much more pronounced. For example, the GSTP1 Val/Valgenotype resulting in the lack of the active enzyme glutathione S-transferase is two times more common in patients diagnosed with diabetes before the age of 40 years, compared with healthy people after the age of $40(18.8 \%$ vs $9.9 \%$; table 4). In turn, the frequency of this genotype does not differ between patients with subsequent diagnosis of diabetes and healthy people ( $10.3 \%$ vs $9.9 \%$; table 4$)$; therefore, it can be assumed that factors other than the GSTP1 genotype prevail in the development of T2D after the age of 40. In a study carried out in Romania, Stoian $e t$ al demonstrated significant differences in the frequency of GSTP1 polymorphism between older patients with T2D (mean age 63 years) and the control group. ${ }^{1}$ Nevertheless, the author does not provide us with the age at which diabetes was diagnosed, which is the basis for the stratification of patients in our study. Analyzing together the homozygous deletion of the GSTT1 and GSTM1 genes, we noticed that the GSTT1 null/null and GSTM1 null/null genotype is much more common in the group of patients diagnosed before the age of $40(18.8 \%)$ in relation to patients with diabetes diagnosed after 40 years of age $(12.5 \%)$ and in comparison to the control group $(8.5 \%)$. However, since these polymorphisms occur together relatively rarely in the population, the number of subjects in the compared subgroups was very low. The observed trend is also confirmed by other studies from around the world. ${ }^{20}{ }^{21}$ Banerjee $e t a l$, in a study on a much larger population (558 with T2D and 410 in the control group), showed a significantly higher frequency of GSTT1 and GSTM1 polymorphisms in patients with T2D than in healthy people. ${ }^{15}$ In addition, our results are in line with the meta-analysis of 25 studies conducted in Asian and Caucasian populations. According to this meta-analysis, combined GSTT1 null/null and GSTM1 null/null genotypes increases the risk of developing diabetes more than twofold. An increase in risk was observed regardless of ethnicity. ${ }^{21}$ For all three genes analyzed, it was noted that as the number of gene combinations increases, there is a rise in the disease risk, especially in the subjects younger than 40, which suggest that a gene-gene interaction plays an important role in T2D susceptibility. Statistically significant differences were demonstrated for the combination of GSTP1 Val/Val and GSTT1null/null genotypes between patients diagnosed before 40 years of age and healthy people $(12.5 \%$ in group A vs $0.9 \%$ in group $\mathrm{C}$, $\mathrm{p}=0.016$; table 4 ), also for the combination of all three genes: GSTP1 Val/Val, GSTT1null/null and GSTM1 null/ null $(12.5 \%$ in group A vs $0.5 \%$ in group $\mathrm{C}, \mathrm{p}=0.013$; table 4). Although the small number of subjects in the groups requires careful conclusions, other authors confirm these results, pointing to even 13.5 times higher risk of developing T2D in the case of such a genotype. ${ }^{15}$

Groups of patients diagnosed with diabetes before the age of 40 (group A; table 4) and patients diagnosed with diabetes after 40 years of age (group B; table 4) did not differ significantly in mean BMI, which suggests that 
Table 4 GST genotype distribution in patients and controls in terms of age of diabetes onset

\begin{tabular}{|c|c|c|c|c|c|c|}
\hline & \multirow{2}{*}{$\begin{array}{l}\text { T2D diagnosed } \\
<40 \text { years old }\end{array}$} & \multirow{2}{*}{$\begin{array}{l}\text { T2D diagnosed } \\
\geq 40 \text { years old }\end{array}$} & \multirow{2}{*}{$\begin{array}{l}\text { Control group } \\
\text { (at age } \geq 40 \\
\text { years old) }\end{array}$} & \multicolumn{3}{|c|}{ P value* } \\
\hline & & & & $A$ vs $B$ & A vs $C$ & B vs C \\
\hline & $n=16$ & $n=184$ & $n=212$ & & & \\
\hline GSTP1 & & & & 0.60 & 0.52 & 0.97 \\
\hline Wild type (Ile/lle) & $6(37.5 \%)$ & $83(45.1 \%)$ & $98(46.2 \%)$ & & & \\
\hline Heterozygous (Ile/Val) & $7(43.8 \%)$ & $82(44.6 \%)$ & $93(43.9 \%)$ & & & \\
\hline GSTP1 & & & & 0.39 & 0.23 & 1.0 \\
\hline Wild type or heterozygous & $13(81.2 \%)$ & $165(89.7 \%)$ & $191(90.1 \%)$ & & & \\
\hline Homozygous (Val/Val) & $3(18.8 \%)$ & $19(10.3 \%)$ & $21(9.9 \%)$ & & & \\
\hline GSTT1 & & & & 0.55 & 0.32 & 0.18 \\
\hline Wild type & $11(68.8 \%)$ & $95(51.6 \%)$ & $120(56.6 \%)$ & & & \\
\hline Null/null & $5(31.2 \%)$ & $89(48.4 \%)$ & $92(43.4 \%)$ & & & \\
\hline \multicolumn{7}{|l|}{ GST combination } \\
\hline P1=wild, T1=wild, M1=null/null & $0(0.0 \%)$ & $32(17.4 \%)$ & $35(16.5 \%)$ & & & \\
\hline P1=wild, T1=null/null, M1=wild & $2(12.5 \%)$ & $8(4.3 \%)$ & $11(5.2 \%)$ & & & \\
\hline P1=wild, T1=null/null, M1=null/null & $1(6.2 \%)$ & $14(7.6 \%)$ & $5(2.4 \%)$ & & & \\
\hline $\mathrm{P} 1=$ heterozygous, $\mathrm{T} 1=$ wild, $\mathrm{M} 1=$ wild & $6(37.5 \%)$ & $38(20.7 \%)$ & $40(18.9 \%)$ & & & \\
\hline $\begin{array}{l}\mathrm{P} 1=\text { heterozygous, } \mathrm{T} 1=\text { wild, } \mathrm{M} 1=\text { null/ } \\
\text { null }\end{array}$ & $1(6.2 \%)$ & $25(13.6 \%)$ & $31(14.6 \%)$ & & & \\
\hline $\begin{array}{l}\text { P1=homozygous, } T 1=\text { null/null, } \\
\text { M1=wild }\end{array}$ & $0(0.0 \%)$ & $1(0.5 \%)$ & $1(0.5 \%)$ & & & \\
\hline $\begin{array}{l}\text { P1=homozygous, } T 1=\text { null/null, } \\
\text { M1=null/null }\end{array}$ & $2(12.5 \%)$ & $3(1.6 \%)$ & $1(0.5 \%)$ & 0.052 & 0.013 & 0.341 \\
\hline $\mathrm{P} 1$ and $\mathrm{T} 1$ & & & & 0.13 & 0.016 & 0.57 \\
\hline P1=wild, T1=wild & $3(18.8 \%)$ & $61(33.2 \%)$ & $82(38.7 \%)$ & & & \\
\hline P1=wild, T1=null/null & $3(18.8 \%)$ & $22(12.0 \%)$ & $16(7.5 \%)$ & & & \\
\hline P1=heterozygous, $\mathrm{T} 1=$ wild & $7(43.8 \%)$ & $63(34.2 \%)$ & $71(33.5 \%)$ & & & \\
\hline P1=heterozygous, $\mathrm{T} 1=$ null/null & $0(0.0 \%)$ & $19(10.3 \%)$ & $22(10.4 \%)$ & & & \\
\hline P1=homozygous, $\mathrm{T} 1=$ wild & $1(6.2 \%)$ & $15(8.2 \%)$ & $19(9.0 \%)$ & & & \\
\hline P1=homozygous, $\mathrm{T} 1=$ null/null & $2(12.5 \%)$ & $4(2.2 \%)$ & $2(0.9 \%)$ & & & \\
\hline $\mathrm{P} 1$ and $\mathrm{M} 1$ & & & & 0.14 & 0.082 & 0.23 \\
\hline P1=wild, M1=wild & $5(31.2 \%)$ & $37(20.1 \%)$ & $58(27.4 \%)$ & & & \\
\hline P1=wild, M1=null/null & $1(6.2 \%)$ & $46(25.0 \%)$ & $40(18.9 \%)$ & & & \\
\hline $\mathrm{P} 1=$ heterozygous, $\mathrm{M} 1=$ wild & $6(37.5 \%)$ & $51(27.7 \%)$ & $50(23.6 \%)$ & & & \\
\hline P1=heterozygous, M1=null/null & $1(6.2 \%)$ & $31(16.8 \%)$ & $43(20.3 \%)$ & & & \\
\hline P1=homozygous, M1=wild & $0(0.0 \%)$ & $7(3.8 \%)$ & $12(5.7 \%)$ & & & \\
\hline P1=homozygous, M1=null/null & $3(18.8 \%)$ & $12(6.5 \%)$ & $9(4.2 \%)$ & & & \\
\hline
\end{tabular}

Continued 


政

Table 4 Continued

\begin{tabular}{|c|c|c|c|c|c|c|}
\hline & \multirow{2}{*}{$\begin{array}{l}\text { T2D diagnosed } \\
<40 \text { years old }\end{array}$} & \multirow{2}{*}{$\begin{array}{l}\text { T2D diagnosed } \\
\geq 40 \text { years old }\end{array}$} & \multirow{2}{*}{$\begin{array}{l}\text { Control group } \\
\text { (at age } \geq 40 \\
\text { years old) }\end{array}$} & \multicolumn{3}{|c|}{ P value* } \\
\hline & & & & A vs $B$ & A vs $C$ & B vs C \\
\hline $\mathrm{T} 1$ and $\mathrm{M} 1$ & & & & 0.21 & 0.14 & 0.43 \\
\hline $\mathrm{T} 1=$ wild, $\mathrm{M} 1=$ wild & $9(56.2 \%)$ & $73(39.7 \%)$ & $98(46.2 \%)$ & & & \\
\hline T1=wild, M1=null/null & $2(12.5 \%)$ & $66(35.9 \%)$ & $74(34.9 \%)$ & & & \\
\hline T1=null/null, M1=wild & $2(12.5 \%)$ & $22(12.0 \%)$ & $22(10.4 \%)$ & & & \\
\hline T1=null/null, M1=null/null & $3(18.8 \%)$ & $23(12.5 \%)$ & $18(8.5 \%)$ & & & \\
\hline
\end{tabular}

*According to the Bonferroni correction, a p-value less than $0.017(=0.05 / 3)$ is considered as statistically significant.

T2D, type 2 diabetes.

body weight had no effect on the onset of diabetes in the studied patient population.

A lack of data regarding diet, which is a weakness of our study, does not allow us to determine possible correlations of eating habits and genotype in the risk of developing T2D, which would be a valuable aspect in discovering the complex mechanisms of the development of this lifestyle disease. Nevertheless, an objective description of patients' eating habits which could lead, over many years, to the development of a metabolic disease such as T2D is very difficult due to the need for long-term retrospective assessment of diet.

A certain limitation is also the small pool of young patients (in whom diabetes appeared before the age of 40 years). However, this confirms the fact that T2D is a disease most commonly associated with adulthood, diagnosed mainly after 40 years of age. ${ }^{46}$

The strength of this study is definitely in the selection of the control group for the age of diabetes diagnosis. This approach is crucial when stratifying groups by age and increases the value of this study in the light of most of the results discussed, where the control group is agematched to the age of patients with diabetes at the time of entry into the study. In addition, it should be emphasized that this study is one of the few in Europe conducted in this subject and the first in Poland.

\section{CONCLUSIONS}

To sum up, the distribution of GST gene polymorphisms assessed in the study does not differ from the published data for the Caucasian race. A higher frequency of GSTP1 $\mathrm{Val} / \mathrm{Val}$, GSTT1 null/null and GSTM1 null/null genotypes has been demonstrated in patients diagnosed with T2D before 40 years of age than in patients who became ill later and healthy subjects from the control group. These differences increase as the number of gene combinations increases. Our results suggest that GST polymorphism may be one of the risk factors for developing T2D at a younger age than the population average, but it need to be confirmed in a larger cohort of young adults.

Acknowledgements We wish to thank the Witamed Diabetes Outpatient Clinic in Kielce for promoting the development of this study, especially to Grażyna
Majcher-Witczak, MD, PhD (Head of the Witamed Clinic), for supervision of patients recruitment and for the support during the study.

Contributors Study conception and design: EO, JuK, SG. Patient recruitment: JuK, BW. Genetic analysis: JuK, JoK. Database building and data interpretation: all authors. Drafting of the manuscript: JuK, KO, EO, BW, EB-S. Critical revision of the manuscript: SG, JoK. Final approval of the version to be published: all authors.

Funding Project financed under the program of Minister of Science and Higher Education called 'Regional Initiative of Excellence' in the years 2019-2022, project no: 024/RID/2018/19, amount of financing 1199900 000zł (Polish zloty). The funders had no role in study design, data collection and analysis, preparation of the manuscript or decision to publish.

Competing interests None declared.

Patient consent for publication Not required.

Ethics approval The study was approved by the Bioethics Committee of the Jan Kochanowski University in Kielce (No 28/2019 of 28 May 2019).

Provenance and peer review Not commissioned; externally peer reviewed.

Data availability statement All data are available on reasonable request.

Open access This is an open access article distributed in accordance with the Creative Commons Attribution Non Commercial (CC BY-NC 4.0) license, which permits others to distribute, remix, adapt, build upon this work non-commercially, and license their derivative works on different terms, provided the original work is properly cited, appropriate credit is given, any changes made indicated, and the use is non-commercial. See: http://creativecommons.org/licenses/by-nc/4.0/.

ORCID iD

Justyna Klusek http://orcid.org/0000-0002-1098-8919

\section{REFERENCES}

1 Stoian A, Bănescu C, Bălașa RI, et al. Influence of GSTM1, GSTT1, and GSTP1 polymorphisms on type 2 diabetes mellitus and diabetic sensorimotor peripheral neuropathy risk. Dis Markers 2015;2015:1-10.

2 Ortega Ángeles, Berná G, Rojas A, et al. Gene-Diet interactions in type 2 diabetes: the chicken and egg debate. Int $\mathrm{J} \mathrm{Mol} \mathrm{Sci}$ 2017;18:1188.

3 International Diabetes Federation. IDF Europe members. Available: www.idf.org/our-network/regions-members/europe/members/152poland.html

4 Polakowska M, Piotrowski W. Incidence of diabetes in the Polish population: results of the Multicenter Polish Population Health Status Study--WOBASZ. Pol Arch Med Wewn 2011;121:156-63.

5 Kozieł A, Pierzak M, Wychowaniec M, et al. Analysis of cognitive disorders in older people with diabetes - preliminary study. Medical Studies 2016;1:23-8.

6 Selph S, Dana T, Blazina I, et al. Screening for type 2 diabetes mellitus: a systematic review for the U.S. preventive services Task force. Ann Intern Med 2015;162:765-76.

7 Raza S, Abbas S, Ahmad A, et al. Association of glutathione-Stransferase (GSTM1 and GSTT1) and FTO gene polymorphisms with type 2 diabetes mellitus cases in northern India. Balkan J Med Genet 2014;17:47-54. 
8 Pahwa S, Sharma R, Singh B. Role of glutathione S-transferase in coronary artery disease patients with and without type 2 diabetes mellitus. J Clin Diagn Res 2017;11:BC05-8.

9 Moasser E, Azarpira N, Shirazi B, et al. Genetic polymorphisms of glutathione-S-transferase M1 and T1 genes with risk of diabetic retinopathy in Iranian population. Iran J Basic Med Sci 2014;17:351-6.

10 Musavi Z, Moasser E, Zareei N, et al. Glutathione S-transferase gene polymorphisms and the development of new-onset diabetes after liver transplant. Exp Clin Transplant 2019;17:375-80.

11 Gönül N, Kadioglu E, Kocabaș NA, et al. The role of GSTM1, GSTT1, GSTP1, and OGG1 polymorphisms in type 2 diabetes mellitus risk: a case-control study in a Turkish population. Gene 2012;505:121-7.

12 Grubisa I, Otasevic P, Despotovic N, et al. Genetic polymorphism of glutathion S-transferase P1 (GSTP1) Ile105Val and susceptibility to atherogenesis in patients with type 2 diabetes mellitus. Genetika 2013;45:227-36.

13 American Diabetes Association. Diagnosis and classification of diabetes mellitus. Diabetes Care 2010;33 Suppl 1:S62-9.

14 Klusek J, Nasierowska-Guttmejer A, Kowalik A, et al. GSTM1, GSTT1, and GSTP1 polymorphisms and colorectal cancer risk in Polish nonsmokers. Oncotarget 2018;9:21224-30.

15 Banerjee M, Vats P, Kushwah AS, et al. Interaction of antioxidant gene variants and susceptibility to type 2 diabetes mellitus. $\mathrm{Br} \mathrm{J}$ Biomed Sci 2019;76:166-71.
16 Bitarafan F, Khodaeian M, Tabatabaei-Malazy O, et al. Influence of antioxidants' gene variants on risk of diabetes mellitus and its complications: a systematic review. Minerva Endocrinol 2019;44:310-25.

17 Mastana SS, Kaur A, Hale R, et al. Influence of glutathione Stransferase polymorphisms (GSTT1, GSTM1, GSTP1) on type-2 diabetes mellitus (T2D) risk in an endogamous population from north India. Mol Biol Rep 2013;40:7103-10.

18 Bid HK, Konwar R, Saxena M, et al. Association of glutathione S-transferase (GSTM1, T1 and P1) gene polymorphisms with type 2 diabetes mellitus in North Indian population. J Postgrad Med 2010;56:176-81.

19 Saadat M. Evaluation of glutathione S-transferase P1 (GSTP1) Ile105Val polymorphism and susceptibility to type 2 diabetes mellitus, a meta-analysis. Excli J 2017;16:1188-97.

20 Orlewski J, Orlewska E. Effects of genetic polymorphisms of glutathione S-transferase genes (GSTM1, GSTT1, GSTP1) on the risk of diabetic nephropathy: a meta-analysis. Pol Arch Med Wewn 2015;125:649-58.

21 Nath S, Das S, Bhowmik A, et al. The GSTM1 and GSTT1 null genotypes increase the risk for type 2 diabetes mellitus and the subsequent development of diabetic complications: a meta-analysis. Curr Diabetes Rev 2019;15:31-43. 